\title{
Pedagogia da Inclusão e a Justiça Restaurativa: escapes com Kafka
}

\author{
Betina Schuler \\ Sônia Regina da Luz Matos' \\ 'Universidade de Caxias do Sul (UCS), Caxias do Sul/RS - Brasil
}

RESUMO - Pedagogia da Inclusão e a Justiça Restaurativa: escapes com Kafka. Este artigo problematiza a pedagogia da inclusão como um discurso majoritário na contemporaneidade, aqui analisada especificamente em sua filiação ao campo jurídico em práticas escolares. Para tanto, escavamos genealogicamente o discurso da Justiça Restaurativa para entender como vem sendo operado na escola para o governo dos riscos. Esburacamos os efeitos de subjetivação nestas práticas escolares de segurança, localizando o rastelo escolar que produz um modo específico de existência, o ofensor, capturado em práticas disciplinares e de controle. Apresentamos uma investigação inspirada no pensamento da diferença e nas galerias da toca kafkiana, experimentando outros modos de existência para o espaço escolar a partir da arte do silêncio como uma ética kafkiana.

Palavras-chave: Pedagogia da Inclusão. Justiça Restaurativa. Kafka.

ABSTRACT - Pedagogy of Inclusiveness and the Restorative Justice: escapes with Kafka. This paper problematizes the pedagogical proposal of inclusiveness as a majority discourse, which is here analyzed specifically in its filiation with the juridical branch in scholarly practices. We genealogically excavate the Restorative Justice discourse to understand how it has been operated at school to govern risks. Hence, we search for the effects of subjectivation in these scholarly practices of security. We try to locate the scholarly ripple, which produces a specific mode of existence, the offender, who now is captured in disciplinary and control practices. In this way, we present this analysis inspired by the thought of difference and by the galleries of Kafka's burrow, trying other modes of existence to the scholarly space from an art of silence as Kafkian ethics.

Keywords: Pedagogy of Inclusiveness. Restorative Justice. Kafka.

Educação \& Realidade, Porto Alegre, v. 39, n. 4, p. 1229-1248, out./dez. 2014. 1229

Disponível em: <http://www.ufrgs.br/edu_realidade> 
Pedagogia da Inclusão e a Justiça Restaurativa

\title{
A Justiça Restaurativa na Toca Kafkiana
}

\begin{abstract}
Que ideia é a tua? Tens uma casa protegida, isolada. Vives em paz, quente, bem alimentado, senhor, senhor absoluto de uma multiplicidade de galerias e praças, e estás disposto, não a sacrificar, esperemos, mas praticamente a abandonar tudo isto; é certo que estás confiante de que podes recuperar tudo, mas vais meter-te num jogo de alto risco, de altíssimo risco? Tens motivos sólidos para isso? Não, não pode haver motivos sólidos para uma coisa destas. Mas mesmo assim levanto o alçapão com cuidado e saio, deixo-o cair com cuidado e corro, corro o mais que posso, para longe desse lugar traiçoeiro (Kafka, 2009, p. 21).
\end{abstract}

Esta escrita busca traçar uma conversação com a escola e seus contemporâneos discursos de inclusão, tal como uma toca que busca proteger dos perigos, mesmo que em potencial. Assim, problematiza esta busca permanente por segurança e identificação dos perigos, pois as falas sobre a escola e a indisciplina, a escola e o conflito, a escola e a violência estão por todo o lugar, escorrendo por todos os lados. A escola na atualidade é parte do dispositivo de segurança ${ }^{1}$, pois sabemos que é atravessada historicamente pelos discursos psi e parece estar sendo, também, invadida pelo discurso jurídico. E é exatamente esse sintoma que aqui será examinado genealogicamente, por meio do pensamento da diferença, com autores como Nietzsche, Foucault e Deleuze e, do mesmo modo, com inspiração na literatura de Kafka, especificamente na obra $A$ Construção (intitulada na tradução para o português de Portugal como $A T$ Toca ${ }^{2}$, edição aqui trabalhada).

Assim, localizamos discursos dessa ordem em algumas escolas públicas de Porto Alegre/RS, dentre eles, o da Justiça Restaurativa, a partir da análise de manuais práticos, publicações referentes a essa experiência e suporte teórico quanto a este projeto, bem como analisamos casos de Círculos Restaurativos ocorridos em Porto Alegre, por meio de entrevistas semiestruturadas com alunos e professores envolvidos em experiências com a Justiça Restaurativa.

As ideias de Justiça Restaurativa vêm se desenvolvendo há mais de três décadas, iniciando em presídios nos Estados Unidos na década de 1970 e depois adotados por outros países, sendo a experiência da Nova Zelândia extremamente relevante, partindo da experiência de algumas práticas de justiça dos aborígenes Maoris. A Justiça Restaurativa (JR) coloca-se como um modo alternativo à justiça retributiva, funcionando por meio da reunião de todos os envolvidos em um ato que causou ofensa, sendo os indivíduos divididos em vítimas e ofensores para decidir coletivamente como lidar com as consequências desse ato, buscando curar a vítima e restaurar o ofensor (Brancher, s/d). Assim, a JR assume que "o diálogo é normativo" (Brancher, s/d, p. 26); ao invés da imposição da dor como normativa no sistema retributivo, entende que "a restaura-

1230 Educação \& Realidade, Porto Alegre, v. 39, n. 4, p. 1229-1248, out./dez. 2014. Disponível em: <http://www.ufrgs.br/edu_realidade> 
ção e a reparação são considerados normativos" (Brancher, s/d, p. 26); ao invés do dano realizado se equivaler ao dano ao ofensor, entende que "o dano praticado se equilibra pela promoção do bem" (Brancher, s/d, p. 26). Ao invés da verdade das vítimas não estar em primeiro lugar, para a JR "as vítimas têm a oportunidade de dizer 'a sua verdade" e "o comportamento responsável é reforçado” (Brancher, s/d, p. 26), em ambientes em que se lamenta a dor da vítima e busca se reintegrar o ofensor à comunidade, conceituando justiça como "as boas relações” (Brancher, s/d, p. 27), sendo que todo o processo apontaria para a reconciliação. Deste modo, para Brancher (s/d, p. 29), "na Justiça Restaurativa, o poder é exercido por consenso. [...] A perseguição de opositores e culpados dá lugar à identificação e satisfação das necessidades de todos, numa relação de responsabilidade mútua".

A partir dessa perspectiva, o Projeto Justiça para o Século 21: Instituindo Práticas Restaurativas inicia em Porto Alegre em 2005, e em algumas escolas em 2007, com o objetivo de pacificar violências, envolvendo crianças e adolescentes por meio de práticas da Justiça Restaurativa, articulada por meio da Associação de Juízes do Rio Grande do Sul (AJURIS) e sob a liderança da $3^{\text {a }}$ Vara do Juizado da Infância e da Juventude em Porto Alegre. Esse Projeto tem financiamento da Secretaria da Reforma do Judiciário, do PNUD (Programa das Nações Unidas para o Desenvolvimento), da UNESCO e Rede Globo, por meio do Programa Criança Esperança, além da contribuição da Secretaria Especial de Direitos Humanos da Presidência da República, através da Subsecretaria de Promoção dos Direitos da Criança e do Adolescente.

Assim, articulado a partir do Poder Judiciário, busca difundir tais práticas nos espaços judiciais e também em espaços não-judiciais. Aguinsky et al. (2008, p. 25) traz que no final de 2004, por meio de um núcleo de estudos de Justiça Restaurativa na AJURIS - Escola Superior de Magistratura, o qual tem sediado quase todos os processos de capacitação, “[...] o projeto começa a estruturar-se elegendo estratégias de progressividade de atuação em 4 áreas: I - JR nos processos judiciais; II - JR no atendimento socioeducativo; III - JR na educação; e IV - JR na comunidade". Como equacionamento metodológico, segundo Brancher e Puggina (2008), Porto Alegre desenvolve suas ações a partir da Comunicação Não-Violenta (CNV), inspirado em Marshall Rosenberg.

A metodologia denominada, pois, de Comunicação Não-Violenta (CNV) busca curar a vítima e reintegrar o ofensor, através de sua autorresponsabilização. Esta metodologia se coloca como atuando com os verdadeiros valores, argumentando que os atos de violência são expressões de necessidades não-atendidas, elencando uma listagem com necessidades humanas universais, tais como: honestidade, respeito, apoio, confiança, harmonia, ordem, paz, graça, entre outras. Desse modo, nos encontros denominados de círculos restaurativos, as necessidades de todos os envolvidos precisam ser levantadas, objetivando-se a autorresponsabilização (Barter, 2008).

Educação \& Realidade, Porto Alegre, v. 39, n. 4, p. 1229-1248, out./dez. 2014.

1231

Disponível em: <http://www.ufrgs.br/edu_realidade> 
Pedagogia da Inclusão e a Justiça Restaurativa

A prática da Justiça Restaurativa, então, se procedimentaliza por meio de um encontro denominado de Círculo Restaurativo (CR), o qual divide-se em três momentos, sendo o processo gerenciado pela figura do coordenador (nas escolas, geralmente esse coordenador é um professor que passou por um processo específico de formação para assumir esse lugar) e reunindo vítima, ofensor e comunidades de apoio (amigos, familiares da vítima e do ofensor). O primeiro momento é o Pré-Círculo, no qual se define o fato ocorrido, bem como os papéis de vítima e ofensor, o que não poderá ser modificado ao longo do processo, sendo a vítima aquela que, geralmente, solicita o CR.

O segundo momento é o Círculo Restaurativo propriamente dito, o qual constitui-se em um encontro que reúne vítima e ofensor, suas respectivas comunidades de apoio, bem como o coordenador. Nesse espaço, a verdade da vítima deverá ser confirmada pelo ofensor, sendo que o mesmo deverá se autorresponsabilizar pelo seu ato perante a comunidade. Nesse momento, o coordenador tem a função de auxiliar na tradução das falas, por meio de perguntas denominadas empáticas ${ }^{3}$, relacionando os sentimentos dos envolvidos, os quais são supostos a partir da fala das pessoas, às necessidades não atendidas das mesmas (metodologia da Comunicação Não-Violenta). E, finalmente, por meio de um consenso, deverá se chegar a um acordo, o qual deverá ter por base as necessidades não-atendidas dos participantes, com o objetivo de reparar as consequências da ofensa praticada. $\mathrm{O}$ acordo trata-se de um plano de ações concretas e quantificáveis, com prazos definidos, identificando o responsável por cada ação. Cada instituição organiza a documentação de registro e repassa os dados a serem inseridos no sistema informatizado de registro (site do Projeto).

O terceiro momento é chamado de Pós-Círculo, em que há a verificação do cumprimento e avaliação do acordo e a retomada do processo para que o fato não se repita e para que todas as necessidades não atendidas sejam recuperadas. Caso o acordo não tenha sido cumprido, pode-se optar pela realização de um novo CR ou demais encaminhamentos, mas o processo não é encerrado caso o acordo não tenha sido realizado conforme o planejado (Brancher, s/d). Os acordos examinados disseram respeito à limpeza da sala de aula e escola pelos alunos, organização de materiais em auxílio ao professor, entre outros pequenos auxílios à escola e professores. Todo este processo é organizado e sistematizado a partir de Manuais, tais como: guias que trazem os passos do Círculo Restaurativo, seus princípios e valores (participação, honestidade, esperança, responsabilidade, empoderamento, humildade, respeito, interconexão) e recolhem dados das vítimas, ofensores e comunidade de apoio, bem como suas assinaturas. Trazem igualmente um resumo dos fatos e espaço para registro das três etapas do CR e do acordo. Existem ainda o termo de acordo e termo de consentimento do processo, entre outros (Brancher, s/d). Grossi et al. (2008, p. 83) traz que, "[...] os acordos devem ser claros, factíveis e com tempo delimitado para

1232 Educação \& Realidade, Porto Alegre, v. 39, n. 4, p. 1229-1248, out./dez. 2014. Disponível em: <http://www.ufrgs.br/edu_realidade> 
serem cumpridos, de modo a que o grau de satisfação dos envolvidos no conflito e a capacidade de restauração das relações sejam verificáveis".

Assim, há uma Central de Práticas Restaurativas do Juizado Regional da Infância e da Juventude (CPR - JIJ) como um espaço interinstitucional, como um centro de difusão das práticas restaurativas, coordenado pela $3^{a}$ Vara da Infância e da Juventude de Porto Alegre, para promover práticas restaurativas em processos judiciais envolvendo crianças e adolescentes. A partir disso se prolongam essas ações para espaços não-judiciais, como as escolas. Assim, ocorrem os Círculos Restaurativos para lidar com infrações às leis (casos tratados em uma Central de Práticas Restaurativas pelo Poder Judiciário) e às normas (casos que são gerenciados pelas escolas, por meio de Círculos Restaurativos, realizados no interior das mesmas, focos de análise deste artigo).

Os círculos restaurativos analisados nas escolas disseram respeito a desentendimentos cotidianos entre estudantes (brigas verbais e físicas) e entre estudantes e professores (por exemplo, um aluno que se recusou a tirar o fone de ouvido dentro de uma sala de aula, um aluno que assoprou no rosto de um professor durante um jogo de futebol em uma aula de Educação Física). Em todos os casos examinados, o lugar do ofensor foi sempre ocupado pelo aluno, o que é um importante sintoma a ser examinado nesta maquinaria. No momento em que um aluno solicitou um CR indicando um professor como ofensor, este não foi levado adiante.

A partir disso, podemos pensar a escola funcionando nessa relação de imanência com a modernidade, a qual realiza fortemente o nexo entre saber e poder na produção desse sujeito moderno. Espaço no qual há todo um disciplinamento dos corpos e saberes, no controle do tempo, do espaço e dos movimentos, ensinando o que temos por realidade, pelos outros, por nós mesmos (Foucault, 2002). São práticas discursivas e não-discursivas na produção de determinados modos de existência. Por isso, podemos examinar a escola no presente por meio da pedagogia da inclusão como um dos elementos do dispositivo de segurança nessa maquinaria jurídico-escolar, funcionando fortemente por meio de diferentes instrumentos na problematização desse corpo a ser restaurado. Trata-se de tomar esse dispositivo atravessando as práticas de si, produzindo determinados modos de subjetivação, em que o indivíduo é tomado como objeto de conhecimento e é produzido nesse processo, no qual se reconhece como um determinado tipo de sujeito em relação a si mesmo. Para Foucault (2003, p. 244), o dispositivo,

[...] engloba discursos, instituições, organizações arquitetônicas, decisões regulamentares, leis, medidas administrativas, enunciados científicos, proposições filosóficas, morais, filantrópicas. Em suma, o dito e o não-dito são os elementos do dispositivo. O dispositivo é a rede que se pode estabelecer entre estes elementos.

Educação \& Realidade, Porto Alegre, v. 39, n. 4, p. 1229-1248, out./dez. 2014.1233 Disponível em: <http://www.ufrgs.br/edu_realidade> 
Pedagogia da Inclusão e a Justiça Restaurativa

O autor vai além, destacando que nesta rede heterogênea de elementos, cada mexida, cada efeito estabelece uma relação de ressonância ou contradição com os outros, o que irá promover uma outra articulação dos mesmos. Assim, quando Foucault (2003, p. 246) afirma que o dispositivo tem uma natureza estratégica, remete para,

[...] uma certa manipulação das relações de força, de uma intervenção racional e organizada nestas relações de força, seja para desenvolvê-las em determinada direção, seja para bloqueá-las, para estabilizá-las, utilizá-las, etc. O dispositivo, portanto, está sempre inscrito em um jogo de poder, estando sempre, no entanto, ligado a uma ou a configurações de saber que dele nascem mas que igualmente o condicionam. É isto o dispositivo: estratégias de relações de força sustentando tipos de saber e sendo sustentadas por eles.

Assim, buscamos aqui analisar como é possível tomar a inclusão como um dispositivo de segurança, que busca prever e controlar os desvios e potenciais riscos, não mais excluindo da escola, mas trazendo para perto para, a partir disso, desenvolver uma rede de saberes e práticas para a produção de certa condução das condutas dos indivíduos tomados como risco, mesmo que em potencial. Desse modo, buscamos analisar uma pedagogia da inclusão se dando por meio das práticas da Justiça Restaurativa na escola e as possibilidades de escape como a ética do silêncio kafkiano. O que está em questão nessa maquinaria é um tipo de experiência de si. Uma experiência do tipo que deposita no interior da identidade aluno, criança, adolescente as regras da moral escolar composta pelo discurso jurídico restaurador. A escola segue, pois, em sua missão civilizatória, na resolução dos problemas de socialização dos aprendizes a humanos. As formas e as tecnologias para restaurar a identidade escolar padrão ficam ao encargo da adultez com seu papel da maturidade e sanidade, dividindo de modo binário os alunos que cabem e os que não cabem na civilidade social e que, portanto, necessitam ser restaurados. Desse modo, temos uma pedagogia da inclusão funcionando na correção dos riscos às normas, tomados como potenciais riscos às leis no futuro, pois, muito mais do que punição, tratam-se de práticas de prevenção do risco.

Esses espaços dividem alunos envolvidos em conflitos em vítimas e ofensores, atravessados por uma lógica pastoral e por aquilo que Foucault denominou de governamentalidade ${ }^{4}$, a qual atravessa as práticas disciplinares $^{5}$, de controle ${ }^{6}$ e as práticas de si mesmo. Assim, temos um funcionamento nessa maquinaria da Justiça Restaurativa que recorre à consciência moralizadora que supostamente nos habita, que nos engole, nos aprisiona dentro de nós mesmos. A maquinaria da Justiça Restaurativa é do tipo metafísica que, como no conto Na Colônia Penal de Kafka (1993), usa a máquina com o rastelo para escrever o veredito no corpo do réu: ofensor, incluído, restaurado. Tal como um animal furun-

1234 Educação \& Realidade, Porto Alegre, v. 39, n. 4, p. 1229-1248, out./dez. 2014. Disponível em: <http://www.ufrgs.br/edu_realidade> 
gador, como o de $A$ Toca de Kafka (2009), que esburaqueia a si mesmo como uma prática do governo de si. Vai-se eficazmente da punição à autorresponsabilização.

Nessas práticas da pedagogia da inclusão para lidar com alunos envolvidos em conflitos na escola, esses corpos governamentalizados assumem-se como réus e carrascos de si mesmos, nesse gerenciamento dos desentendimentos cotidianos, que podem ser brigas entre alunos, desacato por parte de um aluno em relação a um professor, entre outros. Trata-se de um modo do poder se exercer ligando os comportamentos de cada um com formas políticas do governo da conduta, por meio do qual o indivíduo vai se fazendo nas próprias regras desse discurso de verdade que lhe faz prestar contas de si mesmo, em que a consciência se faz jurídica. O indivíduo torna-se conhecível para si e para os demais, sendo a sua verdade constituída e presa a uma lógica documental, uma vez que todo o processo se dá por meio de Manuais que ensinam a como realizar o Círculo Restaurativo, Termos de Consentimento que necessitam ser assinados, Manuais para se inserir os dados dos envolvidos em Protocolos de Acordo com a condição da pessoa (vítima ou ofensor), dados posteriormente digitalizados. Todo este processo é acompanhado pela comunidade de apoio da vítima e do ofensor. Assim, o indivíduo ofensor é constituído como um caso para si e para os demais nessa espetacularização de desentendimentos privados. E isso é tornado possível por meio de técnicas que transformam e fixam a experiência que temos conosco mesmos, ligadas a códigos de norma, formas de saber e modos de subjetivação, levando-os a se reconhecerem como um determinado tipo de sujeito (Foucault, 1994).

O animal de $A$ Toca de Kafka (2009) esburaqueia a toca em busca de um mundo seguro, no qual todos os perigos são afastados, seja excluindo-os, seja trazendo para perto, tal como a pedagogia da inclusão, para manter sob vigilância, seja ainda controlando à distância. $\mathrm{O}$ dispositivo de segurança restaurador da pedagogia é certeza em troca de servidão, nem que seja servidão de si mesmo, desse modelo de humanidade que teima em nos habitar. Uma segurança conquistada por processos burocráticos, administrativamente calculados pela toca: toca-círculo restaurativo, toca-espetáculo, toca-pedagógica, toca-curricular, toca-confissão. São máquinas burocráticas do funcionamento civilizatório do humano feitas sob medida. Sob a medida desse humano inventado e naturalizado, tornado universal pela ciência, pela lei, pela moral e a escola como tendo a função de realizá-lo.

A toca kafkiana traz esse animal paranoico, que constrói para si uma toca em busca de proteção e, ao mesmo tempo, consome-se nela. O animal coloca o problema de sair, de entrar e depois de conviver com esse outro que angustia e traz a incerteza provocada pelas invasões dos supostos perigos que cercam e colocam em xeque a estabilidade. Nos faz pensar nas vidas escolares que passam seu tempo na construção

Educação \& Realidade, Porto Alegre, v. 39, n. 4, p. 1229-1248, out./dez. 2014.1235 Disponível em: <http://www.ufrgs.br/edu_realidade> 
Pedagogia da Inclusão e a Justiça Restaurativa

de uma maquinaria que, enfim, manteria todos os perigos afastados e traria paz e segurança. E nessa obsessão de final feliz, transcendente, esquece-se da vida como imanência. Como traz Kafka (2009, p. 25), “[...] e não é verdade que normalmente é a existência de um faro perfeito a condição de existência do perigo normal”?

\section{Esburacando a Pedagogia da Inclusão}

E também neste caso, como sempre, com inteira justiça, pois quem, mesmo estando de passagem, não alteraria os seus planos de viagem e de futuro ao ver a toca? Mas talvez o animal esteja a escavar sua própria toca, e nesse caso nem sequer posso sonhar com a possibilidade de entendimento. Mesmo que se tratasse de um animal tão especial que a sua toca tolerasse vizinhança, a minha não toleraria, pelo menos não toleraria uma vizinhança audível. [...] o factor decisivo será se o animal sabe de mim, e o que sabe (Kafka, 2009, p. 68-69).

A toca-escola, rotinas, protocolos, manuais, círculos são relações de forças e tecnologias de subjetivação que escorrem pelas paredes úmidas e cheias da espacialidade inclusiva do dentro e do fora. No mundo da inclusão figuram soberanas a identidade, a segurança democrática, a normalidade grotesca e a justiça transcendente. A identidade é convocada a abrir os manuais do humano civilizatório para controlar. E o controle da inclusão tem forma e contorno, tem corpo que lida com as situações-limite.

Nesse mundo binário da espacialidade da inclusão, vive a diferença relativa; essa diferença identitária, que faz uso da classificação, da comparação e da medição para relacionar-se com a vida. Uma diferença parida, grudada em sua relação uterina com a identidade, embora encontremos dissimuladores dentro da toca. A diferença aí aparece como o outro da identidade, como oposição, como a negatividade do mesmo (Deleuze, 2006). Uma espacialidade que, ao mesmo tempo que confirma essa identidade do dentro, nomeia o outro como tendo a necessidade de ser resgatado, pelo salvacionismo pedagógico da inclusão. Como nos traz Kafka (2009, p. 66-67),

$$
\begin{aligned}
& \text { [...] e eu retomo o longo caminho que me leva de volta à pra- } \\
& \text { ça-forte, tudo a minha volta me parece em polvorosa, pare- } \\
& \text { ce observar-me, depois parece desviar o olhar para não me } \\
& \text { incomodar, mas de pronto volto a concentrar-me em mim } \\
& \text { para tentar ler-me no rosto as decisões salvadoras. }
\end{aligned}
$$

Neste contemporâneo modo de governo, a escola, em sua filiação com a moral cristã, não se cansa da obediência incondicional, da confissão da verdade, do apelo à renúncia de si mesmo em nome de valores superiores, que levariam à salvação via inclusão (Foucault, 2008). Trata-

1236 Educação \& Realidade, Porto Alegre, v. 39, n. 4, p. 1229-1248, out./dez. 2014 Disponível em: <http://www.ufrgs.br/edu_realidade> 
-se da condução das condutas nessa comunidade que afirma a crença em uma verdade originária, em uma realidade pré-existente, em um sujeito da consciência pela inclusão. Por isso a importância do instrumento da confissão nesta lógica de decifração e classificação. Estamos falando de uma questão de corpo: do corpo escolar, da massa escolar marcada pela constante necessidade de inspeção, como se sempre houvesse um perigo a rondar. Um perigo que está no interior de si mesmo, em sua identidade desviante, corrompida, estragada, que merece ser restaurada pela inclusão.

Trata-se, pois, do governo das almas e do governo político pela inclusão. Funciona como dispositivo de segurança para trazer os indivíduos para perto, descobrir quem são, como vivem, o que querem, para, então, buscar modificar a experiência de si mesmo nessa maquinaria de verdade e governo que é o Círculo Restaurativo. Diversas são as técnicas de $\mathrm{si}^{8}$ atravessadas pela inclusão que buscam produzir uma determinada consciência de si mesmo, a fim de que o indivíduo se assuma como um determinado tipo de sujeito, autenticado pelos novos especialistas do humano. Neste sentido, aqui poderiam muito mais ser pensadas como técnicas do eu, porque remetem a uma identidade que opera a partir de uma lógica de essência e interioridade a ser revelada, uma vez que as técnicas de si remeteriam muito mais a certas forças e exercícios que colocam em funcionamento determinados modos de subjetivação. Por isso, técnicas do eu orientadas na perspectiva de uma moral prescritiva.

Nas experiências escolares dos Círculos Restaurativos aparecem as arcaicas práticas de exposição e humilhação pública. Além disso, figuram as vigilâncias permanentes, nomeações binárias, sanções, premiações e castigos, exames, confissões, documentações. Somam-se a isso práticas que agora controlam à distância, que espalham o exercício do poder e o dividem em nome da democracia e do consenso, em que o aluno ofensor segue sendo vigiado fora da escola por toda uma comunidade que assume também o lugar de julgamento. A expertise sobre a moralidade do humano é espalhada na comunidade escolar.

Os modos de se lidar com os conflitos nas escolas com os Círculos Restaurativos são transformadas em casos jurídico-escolares, devidamente documentados, informatizados e transformados em estatísticas do medo. E não para serem arquivados, mas inseridos nos sistemas em que os dados estão a todo o momento disponíveis e visíveis, marcando os corpos desses indivíduos também nessa tecnologia da escrita de si, tal como nos alertou Deleuze (2008) sobre as sociedades de controle. O controle está espalhado, generalizado, funcionando ininterruptamente, tal como um rastelo digitalizado. Espetáculo da inclusão. Cálculo do humano. Operacionalização da toca.

Desse modo, as próprias práticas e procedimentos escolares implantados nos Círculos Restaurativos vão se transformando em nossa

Educação \& Realidade, Porto Alegre, v. 39, n. 4, p. 1229-1248, out./dez. 2014.1237

Disponível em: <http://www.ufrgs.br/edu_realidade> 
Pedagogia da Inclusão e a Justiça Restaurativa

pele pedagógica. O animal de Kafka (2009, p. 35) já dizia que "eu e a toca formamos de tal maneira uma unidade". Mas, mesmo trabalhando ininterruptamente, essa maquinaria restaurativa nunca alcança uma seguridade total. $\mathrm{O}$ ataque à moral e à lei é sempre iminente e não há repetição que traga suficiente segurança nessa lógica de que precisamos nos defender, dos outros e de nós mesmos.

Nesse esburacar eterno para descobrir perigos, a escavação se dá como uma escavação de si mesmo, a fim de descobrir os males em si, e buscar, por meio de sua suposta liberdade e autonomia, que o indivíduo-aluno aprenda a educar a si mesmo, se autogovernar, a fim de não repetir infrações contra as normas vigentes. A escola com a função de diagnosticar os perigos, a fim de cumprir sua missão civilizatória e cidadã, funciona como uma toca que se pretende para todos. Todavia, esse todos sendo apenas aqueles ditos administráveis, nomeados e descritos por ciências que assumem o bastão da verdade. Para a toca do século XXI funcionar, novos experts da alma assumem os manuais do humano, como que guardiões da toca, os quais estão sempre à espreita de novos riscos para a invenção de novos manuais, relatórios, modos de falar e perguntar, metodologias, estatísticas, médias, ensinando-nos como devemos ser e como devemos nos relacionar com os demais em se tratando dos conflitos.

Os ruídos da toca são digitalizados, analisados, calculados, ouvidos com atenção e, por fim, transformam-se em estatística em defesa da paz, para que o animal siga sempre atento para conseguir enxergar qualquer intruso, qualquer perigo. A lição que a toca-escola nos ensina: fique sempre com as orelhas bem em pé, nunca relaxe, o perigo sempre ronda, precisamos lutar pela paz e pela segurança, nem que para isso passemos a vida cavando buracos para nós e para os outros. Nem que para isso passemos a vida cavando buracos em nós mesmos, em busca de uma verdade oculta a ser confessada e documentada. Nem que para isso passemos a vida assim: cavando.

Trata-se, pois, de certa fixação pela segurança da identidade padrão, pois “[...] enquanto não se chegar a nenhuma conclusão não posso sentir-me seguro, mesmo que se trate apenas de saber para que lado rolará um grão de areia que se desprende de uma parede" (Kafka, 2009, p. 42). Nem que a toca desmorone em nossas cabeças, não paramos de cavar até acharmos o barulho perturbador. Talvez seja somente a vida em seu tempo.

Nós, seres viventes, habitantes de tocas, nos tornamos objetos para diversas ciências, amarrados a tecnologias políticas, tecnologias de poder. Sujeitos que estudam, falam, produzem, que são incluídos, restaurados e corrigidos na toca, como segurança para determinada produção de realidade. O animal de A Toca de Kafka (2009) jamais deixou de crer na noção de verdade e, talvez por isso, ao invés de aproveitar-se de sua comida, passou a vida a comprar a hipótese da invasão.

1238 Educação \& Realidade, Porto Alegre, v. 39, n. 4, p. 1229-1248, out./dez. 2014. Disponível em: <http://www.ufrgs.br/edu_realidade> 
Nesse meio tempo, a comida estraga. Nesse meio tempo, a vida escorre como água nas paredes das galerias. E mesmo, por vezes, fora da toca, o animal não abre mão do controle, que potencializa-se no mundo do presente, em que todos o encarnam nesse papel de vigilância e restauração de todos.

Mas o que tanto nos assombra? Do que tanto temos medo? O perigo como que esse fio que marca o lado de dentro e o de fora: os bárbaros e aqueles que precisam se proteger deles, os civilizados. E esse outro, pintado como estrangeiro, é extremamente útil para a lógica da mesmidade, uma vez que o indisciplinado confirma a nossa civilidade, o adolescente nossa maturidade, o violento nossa sanidade, o estranho nossa normalidade, o humano estragado nossa bondade.

A escola, nesse funcionamento controlador de animal furungador, diagnostica as ameaças da socialização civilizatória. Em alerta, pergunta-se: trata-se de um barulho ameaçador? Quem faz barulho? O que podemos fazer com ele? Como torná-lo parecido conosco e fazer da sua presença não mais um risco? Como esses modos de ser são atravessados por padrões contemporâneos de segurança? Quem são esses alunos perigosos em potencial? Quem são os traidores pedagógicos que circulam na escola? Por que aterrorizam tanto? Qual o nome deles? Como controlar a periculosidade causada pelo barulho na toca?

A ideia de uma consciência jurídica, que está sendo instalada no espaço escolar, é uma prática na qual os indivíduos marcados como perigosos são colocados em diferentes maquinarias de constante não-esquecimento, de um constante prestar contas de si mesmos. Essa prática escolar julga em nome de valores superiores e trata a identidade perigosa dentro da maquinaria escolar. Tratam-se de tecnologias de disciplinamento e controle social na filiação do discurso jurídico e a escola, que por meio da tecnologia de regulação do Círculo Restaurativo, modifica as experiências que os indivíduos têm de si mesmos, para que todos possam permanecer e desfrutar da segurança da toca. Como eficiência máxima, o autocontrole.

Na pedagogia da inclusão, o Círculo Restaurativo coloca em funcionamento nessa toca jurídico-escolar diferentes modos do poder se exercer e diferentes técnicas de si mesmo, tal como a exposição pública, a confissão, a autorresponsabilização, a documentação, o acordo. É nesse domínio moral que esses indivíduos experimentam-se a si mesmos. $\mathrm{O}$ aluno é posto para narrar a si mesmo em um determinado domínio moral, tal como um momento de autodescoberta, que se mostra como um espaço de fabricação de eus. Tecnologias que produzem uma relação de autoinspeção, de prestação de contas de si mesmo nesse domínio com força de verdade. Assim, reconhecem suas obrigações morais, geridos por experts da restauração, a partir de toda uma metodologia com modos de fala, manuais e relatórios. Um tribunal assumido como uma consciência de si, assumindo para si o olho vigilante, o olho do

Educação \& Realidade, Porto Alegre, v. 39, n. 4, p. 1229-1248, out./dez. 2014.1239 Disponível em: <http://www.ufrgs.br/edu_realidade> 
Pedagogia da Inclusão e a Justiça Restaurativa

saber do expert, tendo aí a regulação das condutas nessa renúncia de si. Uma busca pela obtenção e expressão da verdade de si mesmo, em que a governamentalidade se entrecruza nessas relações, em que as condutas individuais deverão coincidir com os regimes de verdade, com a moral dada, com padrões administrativos de segurança. Vidas diárias transformadas em dados para o governo da população, em estatística, em que se busca a segurança de uns, que se protegeriam de outros: da identidade ofensora.

Pede-se ao intruso que se analise e se confesse, que se abra sem reservas, que se torne um caso para si e para os demais, mas que permaneça na toca. Ao confessar, podemos dizer que a escola só confia no sistema que está sob vigilância. Esse é um tipo de relação moral em formatos jurídicos e pedagógicos que se instauram nas escolas com a prática do Círculo Restaurativo. Práticas de tribunais generalizados, assumidos como modos de existência na toca-escolar para inclusão. A toca, assim, "proporciona paz a quem se lhe abrir sem reservas" (Kafka, 2009, p. 32).

E, então, pensa o animal da toca, tudo que causa estranhamento, não deve ser bom, nem representante do bem. A certeza que se tem é que os vereditos científicos e jurídicos estão sempre do lado do bem, buscando transformar a experiência de si mesmo destes perigos/barulhos/estrangeiros que rondam a mesmidade. E, como eficiência máxima, o Círculo Restaurativo governa os vivos na toca dos musgos.

Todas as ensinagens governam: desde a tabuada, os rios, os plurais até os modos que devemos governar a nós mesmos em se tratando aqui, especificamente, dos modos de se lidar com conflitos na escola. Governam em nome de certos discursos de verdade, por meio de específicas tecnologias de extração e fixação da verdade de si mesmo. A toca das totalidades e das universalidades prometem segurança e inclusão para o mundo dos perigos em potencial. A maquinaria jurídico-pedagógica da inclusão confirma mais uma vez essa espacialidade moderna do dentro e do fora; a espacialidade da identidade majoritária originária. Burocracia arcaica, atualizada com novas linguagens, novos nomes para falar do mesmo, para falar da mesmidade, do sujeito da alma, da consciência, da identidade. Com sua não-discutível verdade, porque luta pela paz classificatória e seus discursos metafísicos, funciona na valoração da ordem do transcendente. Assim, aguardam o incluído ter um espaço do céu.

Podemos, também, experimentar um modo mais genealógico de viver na toca, temporariamente nada identitário (Nietzsche, 2006; Foucault, 2002; 2011). Esse modo de escavação genealógica é feito na superfície das galerias e praças que foram construídas. Na superfície temos mais possibilidades de capturar os discursos e os efeitos específicos de poder e subjetivação. Com a genealogia perguntamos quais são as conexões entre estratégias de poder, modos de saber e constituição das

1240 Educação \& Realidade, Porto Alegre, v. 39, n. 4, p. 1229-1248, out./dez. 2014 Disponível em: <http://www.ufrgs.br/edu_realidade> 
experiências de si nestas práticas de inclusão. Inclusão que nos fecha. E que nos fecha por dentro. Porque opera com um dentro. E que opera sob a bandeira da paz. Que se coloca em um local não passível de problematização, pois milita em nome do bem.

Pensar em outra potência de vida? Então esqueçamos temporariamente as identidades da toca. Entremos nos espaços de uma ética do escape como parte de um plano mais genealógico escolar, o qual sintomatologiza o espaço controlador que constatamos até agora e pergunta-se: quais são os efeitos de poder e subjetivação do funcionamento dessa pedagogia da inclusão? Quais são as microburocracias que buscam dobrar os indivíduos/barulhentos? O que elas nos ensinam a desejar? Como as resistências/ruídos e as invenções/barulhos produzem uma outra ética de existir, que não seja a determinada pela majoritária inclusão escolar?

\title{
A Ética do Escape Kafkiano: a arte do silêncio
}

\begin{abstract}
Acabei de construir a toca e parece-me que ficou bem. É certo que, de fora, a única coisa que se vê é um grande buraco, mas um buraco que não conduz de facto a lado nenhum, dois ou três passos adiante dá-se de caras com um muro natural de rocha. Não quero gabar-me de ter tramado este ardil com premeditação, pois foi apenas o que restou de uma das muitas tentativas falhadas de construir uma casa, mas acabei por achar vantajoso deixar este buraco, e só este, destapado. [...] a prudência manda que eu tenha sempre uma possibilidade de saída imediata, e também manda que, como infelizmente acontece tantas vezes, eu arrisque a vida (Kafka, 2009, p. 5-6).
\end{abstract}

A ética do escape pode conversar com a justiça inclusiva na perspectiva da imanência dos acontecimentos. Fala a partir da exterioridade e do acaso, sem valores totais. Pergunta pelas condições de possibilidade dos ruídos fora dessa arena autorizada que produz a violência como um espetáculo governável. Conseguiríamos nós sobrevivermos nos escapes pedagógicos? Conseguiríamos conviver com existências não demarcadas pela identidade? Conseguiríamos viver sem os manuais do humano? Poderíamos mudar as perguntas pedagógicas? Poderíamos pensar as intervenções na escola nos momentos de conflito, na violência não como plano de defesa, de proteção da toca, da identidade, da normalidade? Conseguiríamos conviver com a vizinha barulhenta, com o som fora do aceitável, escapando desse achatamento da diferença?

Pensemos, por um momento, as intervenções escolares dentro dos conflitos; estes como parte das relações de forças que agitam as fronteiras entre a toca e os estranhamentos. Não podemos desautorizar as forças do conflito. As forças da violência do conflito jurídico da inclusão não são ingênuas, porque elas são parte do jogo das fronteiras.

Educação \& Realidade, Porto Alegre, v. 39, n. 4, p. 1229-1248, out./dez. 2014.1241

Disponível em: <http://www.ufrgs.br/edu_realidade> 
Pedagogia da Inclusão e a Justiça Restaurativa

As forças são fluxos de poderes e os perigos modos de forças de afetar e ser afetado pela violência das fronteiras. São as forças dessa afetação que envolvem o cotidiano escolar. A força não se dá, não se troca e nem se retoma, mas se exerce, só existe em ação, em relação. Ela é sempre difusa, espalhando-se por toda parte, microfisicamente. A agitação das forças movimenta o jogo da desterritorialização da violência negativa, possibilitando que os ruídos sejam parte da tensão que atravessa as relações sociais e que, talvez, possam funcionar como formas de afirmar a vida, a criação.

Com estes conceitos pensamos a escola como constante conflito, o que é diferente da toca veriditosa, que disciplina e controla o conflito. Com esses campos conceituais não podemos e não queremos prometer salvação, nem inclusão, nem o bem, muito menos o bom. Com esse jogo de forças podemos acionar o vitalismo pedagógico, nada ingênuo e muito menos romântico do final feliz, porém vivo.

Como apita Kafka (2009, p. 7-8) pelos corredores cinzentos e com nevoeiro, “[...] pelo sim, pelo não, o melhor é tomar a precaução de ter sempre por perto uma saída acessível, completamente desimpedida, pela qual possa escapar [...]". E, como segue dizendo, "é sempre com certo alvoroço que me aproximo da saída” (Kafka, 2009, p. 17). Uma opção pela diferença como diferença, na possibilidade de infinitos modos de estar no mundo. Infinitos modos de se lidar com os acontecimentos.

Tentativas de viver práticas escolares, entre pessoas envolvidas em desentendimentos, sem termos que assumir identidades definidoras e divisoras. Essa prática é parte do jogo de escape com as forças que afirmam a vida pela diferença. Conversação no fortalecimento das diferenças pela diferença ao invés da confissão. Talvez, problematizar em nós mesmos os lugares que ocupamos na toca-escolar. Ainda, criarmos espaços de saídas para não cairmos, em todos os instantes, em julgamentos moralizadores rasos, em discursos disponíveis já maquinados para o encaixe em manuais disciplinadores, os quais corroboram com os poderes instituídos para produzir a violência negativa e a identidade do ofensor.

Não existe um ideal nas relações humanas. O que temos são pessoas vivendo situações, intensidades, forças, ideias, corpos, movimentos. Por isso a ética é uma questão de corpo-vida, como nos traz Onfray (2009) a partir de Nietzsche, e não uma moral superior, totalizada fora do tempo e do espaço. Daí uma aposta em um jogo imanente e não a submissão a um céu. A imanência trata de uma ética modesta, onde as pessoas são capazes de produzir efeitos na sua própria existência. Nesse sentido, os contratos que se fazem entre as pessoas e a vida estão nos exercícios que ponham em constante experimentação a prática das intensidades sensíveis do possível.

E uma ética não existe sem a relação com o outro. E essa relação com o outro pode ser da ordem do interessar-se pela delicadeza do cui-

1242 Educação \& Realidade, Porto Alegre, v. 39, n. 4, p. 1229-1248, out./dez. 2014 Disponível em: <http://www.ufrgs.br/edu_realidade> 
dado. Viver a ética que passa, em dados instantes, por situações de distância e afastamento, quando o desejo não é o da convivência. Políticas mínimas, alianças provisórias, resistências locais. Construção de contratos, relações entre encontros, condições de possibilidades. O encontro não pode ser um castigo, mas uma opção sempre em aberto, uma equipagem para uma certa estética da existência.

Talvez experimentarmos na toca-escolar, tão burocratizada, calculada, digitalizada, administrada, binarizada, esquadrinhada, com seus guias, manuais, livros de ocorrências e tudo mais como um espaço de vida, um espaço do corpo, de relações mais alegres em escapes inventados. Trata-se de um tipo de deslocamento ínfimo, para um ater-se ao cuidado de si, sobre o qual Foucault $(2007 ; 2011)$ escreveu. Um cuidado ao que se passa e ao que se passa no pensamento, no sentido de buscar escapar o máximo possível da escravidão, seja de si ou do outro. Da escravidão que nessa maquinaria opera com o modelo da vítima no discurso da Justiça Restaurativa. Para além da renúncia de si, o que estaria, nessa perspectiva em questão, seria justamente o deslocamento de si. Ao invés de se tornar um objeto de conhecimento em relação ao risco, periculosidade, normalidade em se tratando da discussão aqui em questão, a opção por exercícios que coloquem em funcionamento uma certa estética da existência para além do rebanho do tu deves (Nietzsche, 2006). Trata-se, pois, não de um vale-tudo, mas, estoicamente pensando, em uma equipagem de vida, na vida, para a vida, tomada em sua imanência. Uma ética do escape para além das explicações fáceis e rasas do funcionamento do humano, que vem sendo gerenciado pelos especialistas da alma. Uma ética que talvez busque outras relações que não sejam da ordem do apequenamento, mas da potencialização da diferença.

As escolhas pedagógicas e seus contratos de responsabilizações se dão a partir de muitos mundos. Falamos dos muitos mundos que o autor Kafka escreveu e que nos aciona um tipo de vitalismo, que denominamos de escape. Escapamos, temporariamente com Kafka, das totalidades, das certezas educativas, da transcendência, dos lugares binários, das promessas de salvação, da metafísica, do ideal ascético, do disciplinamento, das identidades e verdades já disponíveis de antemão que marcam os encontros em pactos binários, em consciências jurídicas ${ }^{9}$. Ainda com Kafka, apostamos em esculpir a nós mesmos com a ética do escape. A partir da toca, quem sabe, também experimentarmos viver encontros inusitados, esculpindo-nos eticamente, escapando temporariamente das estreitezas em uma convocação à vida. Isso não diz respeito a um final feliz ou a um novo projeto de libertação. Tratam-se de algumas experimentações de pensamento e vida em se tratando do espaço escolar.

Falemos, pois, do não lugar da galeria inclusiva, galeria sem expectativa. Silêncio de galerias, um silencioso furungador a partir de Ka-

Educação \& Realidade, Porto Alegre, v. 39, n. 4, p. 1229-1248, out./dez. 2014.1243 Disponível em: <http://www.ufrgs.br/edu_realidade> 
Pedagogia da Inclusão e a Justiça Restaurativa

fka, um artista do silêncio. São múltiplos os escapes pedagógicos diante da inclusão. A inclusão nunca é muda nem cega. Ela acopla-se com os discursos da Justiça Restaurativa; do Círculo Restaurativo; do ofensor; da listagem de valores universais, na qual as falas deverão ser encaixadas; dos acordos verificáveis e calculáveis; dos manuais de toda ordem. Nas galerias escolares ouvir os ruídos, então, faz-se uma necessidade de parada para o silêncio.

E nos deparamos, então, com a arte do silêncio nietzschiano como uma necessidade de exercício (Nietzsche, s/d). A arte do silêncio não tem nada a ver com fazer silenciar. O que há é um constante processo de captura do atual. Intensidade de uma vitalidade quase frágil, uma força frágil do silêncio. Ele parece afetar as teorias pedagógicas jurídicas da inclusão nessa justiça que restaura como uma déspota da inclusão. Justiça essa que faz a enunciação da negação da vida, usando o jogo moral como força do disciplinamento e do controle. Por isso, a relevância da arte do silêncio para fazer cessar essa enunciação. Um silêncio que, para além de uma tagarelice que produz uma existência distraída, constitui-se como uma arte ruminada do cuidado.

O silêncio é superfície, nada de profundidade moral. Apenas corpos que forçam a arte do silêncio no aparato pedagógico, na dissolução de identidades moralizadoras. Trata-se de um tipo de silêncio sem modelos e cópias, sem representação. Este corpo, não jurídico, faz a arte do silêncio por dentro das galerias ao modo kafkiano. Este tipo de arte é polifônica da diferença pela diferença. Uma diferença da ética do escape que afirma a vida (Nietzsche, s/d). O escape aqui é uma prática de silêncio diante da pedagogia da inclusão.

Silenciosas galerias kafkianas que vivem na dureza do portal da toca-pedagógica-inclusiva por meio da Justiça Restaurativa na escola. O Círculo Restaurativo e seus juízes morais fazem a avaliação no portal da toca-escolar. Daí a potência dos corpos e dos fluxos que fazem do silêncio um escape, uma ética da diferença em meio à vida. Uma arte que ouve o silêncio da diferença e que não vive por uma pedagogia da inclusão. Vive de modestos escapes nessa toca-escolar. Nessa toca que construímos para proteção e segurança e, quando vemos, somos por ela engolidos. Por isso a importância da sábia recomendação de Kafka (2009): deixar brechas de respiro, saídas, escapes!

Recebido em 15 de agosto de 2013 Aprovado em 11 de julho de 2014

\section{Notas}

1 Este dispositivo está ligado ao controle dos indivíduos e da população (Foucault, 2003; 2008), o qual busca certa organização das forças para controlar os possíveis desvios em uma população, os possíveis riscos, no sentido de gerenciá-los em nome da segurança e bem-estar da mesma. Nesse sentido, o dispositivo se articula em práticas discursivas e não-discursivas, a partir de certos campos

1244 Educação \& Realidade, Porto Alegre, v. 39, n. 4, p. 1229-1248, out./dez. 2014. Disponível em: <http://www.ufrgs.br/edu_realidade> 
de saber, tais como as ciências humanas e jurídicas no caso desta investigação, e certos exercícios de poder. O dispositivo de segurança é aqui analisado atravessado pela inclusão, colocando em funcionamento discursos, instituições, normas, técnicas para circularem na escola e produzirem seus efeitos, sendo o principal deles as identidades de ofensor e vítima fabricadas. Trata-se de um dispositivo que operacionaliza de uma determinada maneira as relações de força, buscando a transformação dos indivíduos em nome de uma sociedade mais segura, com uma crescente intervenção do Estado na vida dos indivíduos, nas suas condutas, em que todos deverão controlar a todos.

2 A Toca foi escrita no último ano de vida de Kafka e não foi terminada. Esta obra traz a história de um animal que construiu para si uma toca em busca de proteção e segurança. E a cada barulho, surge o medo da invasão, a criação de hipóteses de quem seriam os inimigos e a criação de estratégias de proteção da mesma por entre as galerias construídas. Todavia, a vontade de sair acompanha o funcionamento do animal, que busca sempre deixar uma saída em aberto.

3 Conforme Brancher (s/d, p. 42), “[...] o Coordenador poderá auxiliar a vítima a compreender a si própria e a ser compreendida pelos outros presentes, formulando perguntas empáticas, que sondem a correspondência entre seus sentimentos e suas necessidades. Estas perguntas se baseiam na indagação: 'Você se sente ... porque você precisa de ...?’ O primeiro espaço (...) é preenchido por um sentimento que o coordenador suponha e o interlocutor esteja experimentando. O segundo espaço (...) é preenchido por uma possível necessidade subjacente a este sentimento. [...]. Por exemplo: 'Você se sente com medo porque precisa de segurança?' [...]. Como as necessidades correspondem a valores universais, o Coordenador pode arriscar ('chutar') qualquer deles, cuja adequação poderá ser confirmada, ou será espontaneamente substituída pelo interlocutor por aquele valor que considere mais adequado".

4 Termo trazido por Foucault (2008) quando da passagem (o que não significa substituição) do poder pastoral para a governamentalidade, agora com uma preocupação com o governo político dos homens, como o campo estratégico das relações de poder, no qual se dão a condução das condutas. Pode ser pensada como um modo de racionalidade governamental imanente aos micropoderes, tendo na população seu principal objetivo, fazendo os recortes entre o que cabe ou não ao Estado, separando o público do privado, o que hoje se borra na tecnologia do Círculo Restaurativo, quando se espetaculariza desentendimentos privados. $\mathrm{O}$ conceito de governamentalidade diz respeito à regulação da população, focado nos mecanismos de segurança. Somos levados a nos reconhecermos como parte de uma nação, de um Estado, sob suas normas e leis. Uma racionalidade que põe em funcionamento variadas técnicas e saberes científicos para verificação e melhora das condutas, da riqueza, da saúde, da educação, da pacificação. A governamentalidade cruza as técnicas disciplinares, o exercício do biopoder na gestão da população e as condutas de si mesmo, como práticas de governo. Assim, Foucault (2008) tratou da governamentalidade relacionando segurança, população e governo, em que se busca certa condução das condutas dos indivíduos.

5 Foucault (2002) refere-se ao poder disciplinar como fortemente atravessado na constituição da sociedade moderna, em que o corpo torna-se objeto e alvo do poder. Nesse contexto, variadas estratégias são utilizadas, permitindo o domínio minucioso das operações do corpo, através de relações microfísicas. Foucault refere-se que, são "[...] esses métodos que permitem o controle

Educação \& Realidade, Porto Alegre, v. 39, n. 4, p. 1229-1248, out./dez. 2014.1245

Disponível em: <http://www.ufrgs.br/edu_realidade> 
Pedagogia da Inclusão e a Justiça Restaurativa

minucioso do corpo, que realizam a sujeição constante de suas forças e lhes impõem uma relação de docilidade-utilidade, são que podemos chamar as 'disciplinas'” (Foucault, 2002, p. 118), as quais funcionam no sentido de se apropriar das forças, multiplicá-las, ordená-las, separá-las, diferenciá-las. E, neste microdetalhamento do corpo, operam instrumentos disciplinares, tais como a vigilância hierárquica, a sanção normalizadora e o exame.

6 Deleuze (2008) tratou das sociedades de controle, retomando as sociedades disciplinares que Foucault estudou, procedendo às instituições de confinamento, no qual o indivíduo passaria de um espaço fechado a outro, e agora outras forças entrando em funcionamento depois da Segunda Guerra Mundial. $\mathrm{O}$ autor aponta a crise que as instituições de confinamento estão passando e pelas inúmeras reformas que vêm sofrendo, sendo as sociedades de controle a estarem também se operando: formas de controlar ao ar livre, em que o controle substituiria o exame. Para Deleuze (2008, p. 225), “[...] pode ser que meios antigos, tomados de empréstimo às antigas sociedades de soberania, retornem à cena, mas devidamente adaptados. O que conta é que estamos no início de alguma coisa". Neste sentido, o controle pode ser entendido a partir de Deleuze (2008) como esse modo de funcionamento do poder, em que todos vigiam a todos, na qual se controla o controle. Tal conceituação deleuziana nos remete ao espaço do Pós-Círculo do CR, em que se realiza a verificação do acordo e se refaz tantas vezes quanto se julgar necessário, podendo ser visto como um panóptico generalizado, primando por sistemas que permitam uma visibilidade permanente (tal como uma comunidade que segue vigiando os indivíduos para além dos muros da escola). Um tribunal espalhado, sendo que qualquer um pode acioná-lo, participar, julgar, sugerir acordos, enfim, disparar a maquinaria. Trata-se de um controle ininterrupto, contínuo, nos quais nos tornamos dados, informações sempre disponíveis, visíveis.

7 Esta obra narra a visita de um explorador estrangeiro a uma Colônia Penal, apresentada pelo oficial responsável por seu funcionamento. Nesta visita, o oficial apresenta detalhadamente ao explorador o funcionamento da máquina de execução e um condenado, esclarecendo que o condenado não sabe de sua sentença até a ter inscrita na carne pelo rastelo da máquina (que corresponde à forma do humano). Assim, leva-se em consideração que a culpa é sempre indubitável e que a máquina, segundo o oficial, funciona mesmo sozinha e produz seus efeitos.

8 Para Foucault $(1994$, p. 1), as técnicas de si são aquelas que “[...] permite aos indivíduos efetuarem, sozinhos ou com a ajuda de outros, um certo número de operações sobre seus corpos e suas almas, seus pensamentos, suas condutas, seus modos de ser; de transformarem-se a fim de atender um certo estado de felicidade, de pureza, de sabedoria, de perfeição ou de imortalidade".

9 Para Larrosa (2000, p. 73), o processo do sujeito se narrar num “[...] domínio moral, a consciência se faz jurídica. O ver-se, o expressar-se e o narrar-se no domínio moral se constituem como atos jurídicos da consciência. Isto é, atos nos quais a relação da pessoa consigo mesma tem a forma geral do julgar-se".

\section{Referências}

AGUINSKY, Beatriz Gershensos et al. A Introdução das Práticas de Justiça Restaurativa no Sistema de Justiça e nas Políticas da Infância e Juventude em Porto Alegre: notas de um estudo longitudinal no monitoramento e avaliação do pro-

1246 Educação \& Realidade, Porto Alegre, v. 39, n. 4, p. 1229-1248, out./dez. 2014 Disponível em: <http://www.ufrgs.br/edu_realidade> 
jeto justiça para o século 21. In: BRANCHER, Leoberto; SILVA, Susiâni (Org.). Justiça para o Século 21: instituindo práticas restaurativas: semeando justiça e pacificando violências - três anos de experiência da justiça restaurativa na capital gaúcha. Porto Alegre: Nova Prova, 2008. P. 23-57.

BARTER, Dominic. Comunicação Não-Violenta: uma base ética para práticas restaurativas. In: Justiça para o Século 21: instituindo práticas restaurativas. material de apoio - curso de formação em práticas restaurativas. Disponível em: <www.mj.gov.br>. Acesso em: 10 abr. 2008.

BRANCHER, Leoberto. Justiça para o Século 21: Instituindo Práticas Restaurativas - Iniciação em Justiça Restaurativa. Porto Alegre, s/d.

BRANCHER, Leoberto; PUGGINA, Rodrigo. Núcleo de Estudos em Justiça Restaurativa da Escola Superior de Magistratura. In: BRANCHER, Leoberto; SILVA, Susiâni. Justiça para o Século 21: instituindo práticas restaurativas: semeando justiça e pacificando violências - três anos de experiência da justiça restaurativa na capital gaúcha. Porto Alegre: Nova Prova, 2008. P. 91-93.

DELEUZE, Gilles. Diferença e Repetição. Tradução de Luiz Orlandi e Roberto Machado. Rio de Janeiro: Graal, 2006.

DELEUZE, Gilles. Conversações. Tradução de Péter Pal Pelbart. São Paulo: Ed. 34, 2008.

FOUCAULT, Michel. As Técnicas de Si. Tradução de Wanderson Flor do Nascimento e Karla Neves a partir de Michel Foucault. In: FOUCAULT, Michel. Dits et Écrits. Paris: Gallimard, v. IV, 1994. P. 783-813.

FOUCAULT, Michel. Vigiar e Punir: nascimento da prisão. 25. ed. Tradução de Raquel Ramalhete. Petrópolis: Vozes, 2002.

FOUCAULT, Michel. Sobre a História da Sexualidade. In: FOUCAULT, Michel. Microfísica do Poder. 10. ed. Tradução de Roberto Machado. Rio de Janeiro: Graal, 2003. P. 243-276.

FOUCAULT, Michel. História da Sexualidade, 3: o cuidado de si. 9. ed. Tradução de Maria Thereza da Costa Albuquerque. Rio de Janeiro: Graal, 2007.

FOUCAULT, Michel. Segurança, Território e População: curso dado no Collège de France (1977-1978). Tradução de Eduardo Brandão. São Paulo: Martins Fontes, 2008. (Coleção Tópicos).

FOUCAULT, Michel. A Hermenêutica do Sujeito: curso dado no Collège de France (1981-1982). 3. ed. Edição estabelecida por François Ewald e Alessandro Fontana, por Fréderic Gros. Tradução de Marcio Alves da Fonseca, Salma Tannus Muchail. São Paulo: Martins Fontes, 2011.

GROSSI, Patrícia Krieger et al. Justiça Restaurativa nas Escolas de Porto Alegre: desafios e perspectivas. In: BRANCHER, Leoberto; SILVA, Susiâni. Justiça para o Século 21: instituindo práticas restaurativas: semeando justiça e pacificando violências - três anos de experiência da justiça restaurativa na capital gaúcha. Porto Alegre: Nova Prova, 2008.

KAFKA, Franz. Na Colônia Penal. Tradução de Modesto Carone. 4. ed. São Paulo: Editora Brasilense, 1993.

KAFKA, Franz. A Toca. Tradução de Francisco Agarez. Lisboa: LxXL Edições, 2009.

LARROSA, Jorge. Tecnologias do Eu e Educação. In: SILVA, Tomaz Tadeu da (Org.). O Sujeito da Educação: estudos foucaultianos. 4. ed. Petrópolis: Vozes, 2000. P. 35-86.

Educação \& Realidade, Porto Alegre, v. 39, n. 4, p. 1229-1248, out./dez. 2014.1247

Disponível em: <http://www.ufrgs.br/edu_realidade> 
NIETZSCHE, Friedrich. Assim falou Zaratustra. Um livro para todos e para ninguém. Tradução de Mário da Silva. São Paulo: Circulo do Livro, s/d.

NIETZSCHE, Friedrich. A Genealogia da Moral. Tradução de Paulo César de Souza. São Paulo: Companhia das Letras, 2006.

ONFRAY, Michel. A Potência de Existir: manifesto hedonista. Tradução de José Luiz Pérez. Lisboa: Campo da Educação, 2009.

Betina Schuler é doutora em Educação (PUCRS). Pós-Doutorada em Educação pela Universidade de Lisboa. Pós-Doutorada em Ciências Humanas pela Griffith University, Austrália. Professora no Centro de Filosofia e Educação e no Programa de Pós-Graduação em Educação da Universidade de Caxias do Sul, na linha de História e Filosofia da Educação. Pesquisadora no Observatório de Educação na Universidade Federal do Rio Grande do Sul e na Universidade de Caxias do Sul.

E-mail: betinaschuler@yahoo.com.br

Sônia Regina da Luz Matos é professora no Centro de Filosofia e Educação da Universidade de Caxias do Sul. Doutoranda em Educação pelo PPGEdu/ UFRGS e Laboratoire Santé, Individu, Société EAM-SIS-HCL 4.128, Université de Lyon2/França. Pesquisadora no Observatório de Educação da UFRGS e UCS.

E-mail: sonia_matos@bol.com.br 